\title{
Inventario sistematizado de los estudios culturales existentes sobre los pueblos de la Costa Caribe de Nicaragua. Un primer acercamiento
}

\author{
María Dolores Álvarez Arzate'
}

\section{INTRODUCCIÓN}

La Costa Caribe de Nicaragua ha sido, con toda certeza, una de las áreas de América Central, histórica y geopolíticamente, más dinámicas de la región. El territorio y su población constituyen un todo indisoluble en donde se desarrollan intensos procesos sociales y culturales de importancia a todos los niveles.

Historiadores, sociólogos, antropólogos, autodidactas, entre otros, se han dado a la tarea de estudiar esta historia y de comprender hechos sociales de configuración particular y única, como la autonomía y la multiculturalidad. Por ello es sabido que existen muchos estudios generados desde centros académicos, instituciones e intereses particulares dentro y fuera de la Costa Caribe. De allí la necesidad de elaborar un inventario que sea una aproximación de la amplitud y caudal de los materiales existes

E1 Programa Conjunto Revitalización Cultural y Desarrollo Productivo Creativo en la Costa Caribe de Nicaragua tiene como uno de sus componentes, la realización de este inventario sistematizado de los estudios culturales existentes sobre los pueblos de la Costa Caribe de Nicaragua. El presente documento informa sobre la metodología y los resultados de la investigación de dicha sistematización, lo que servirá como soporte para el desarrollo del Fondo de Investigaciones para la Revitalización Cultural.

El inventario y su exposición brindan la información acerca de la bibliografia localizada y las posibles áreas de intervención para el impulso de nuevas investigaciones culturales, arqueológicas, creativas así como traducciones pertinentes. Al final de esta presentación, el lector encontrará un listado de siglas y acrónimos utilizados.

\section{METÓDICA}

Entre los aspectos metodológicos más importantes debemos señalar que la construcción de la base de datos en formato Excel llevó dos momentos, (a) el uso exclusivo de columnas para insertar los datos en filas y (b) su modificación, a partir de la revisión preliminar en UNESCO Costa Rica. En cuanto al uso del sistema de clasificación hubo un período de ensayo; se inició con el sistema Melvil Dewey, de uso muy frecuente en las bibliotecas de nuestro país, y posteriormente se asumió el Tesauro de UNESCO.

La base de datos de Excel contiene una columna específica que hace el hipervínculo entre el registro bibliográfico con el registro fotográfico. Esto permite a los usuarios de la base de datos tener la referencia visual del texto o documento incluido en la sistematización.

Se incluyen en la sistematización, las publicaciones de dos periódicos Autonomía y Sunrise; dos revistas Wabul y El Costeño; y 2 boletines El Saslaya y Minero. Estos materiales fueron localizados en colecciones personales (ejemplares aislados), en el Instituto de Historia de Nicaragua y de Centroamérica, en URACCAN Bilwi, y en CIDCA Bilwi. En los lugares referidos, estos materiales no se encuentran disponibles debido a su avanzado estado de deterioro y precarias condiciones de almacenamiento.

La localización de fuentes a través del formato electrónico de banda ancha permitió identificar positivamente 27 fuentes relevantes entre sitios webs y blogs de tipo académico.

La metódica de la investigación permite poner en evidencia y dar prueba fehaciente de que existen importantes esfuerzos de investigación y de comunicación sobre la

1 Con la colaboración de Bayardo Gámez Montenegro 
cultura de las poblaciones de la Costa Caribe de Nicaragua, los cuales deberán seguir ampliándose y sistematizándose en forma cíclica con el apoyo de los distintos actores sociales involucrados.

Durante el trabajo de campo, se pudo comprobar, como resultado no esperado, la existencia de valiosos archivos institucionales de instancias que abordan el tema de la Costa Caribe en general y en donde posiblemente se encontrará importantes datos para investigaciones futuras, por ejemplo, los archivos de la consulta regional sobre la Autonomía (1985-1987), archivos y centros de documentación de las organizaciones, organismos no gubernamentales, Gobiernos Regionales, Alcaldías, Ministerios de Salud, Educación, Sistema Judicial, Gobernación, de Relaciones Exteriores y Asamblea Nacional.

También se pudo constatar que, tanto en las institucionales como en personas privadas, existen materiales sobre estudios culturales con otros formatos no bibliográficos, los cuales podrán incluirse en nuevas investigaciones, tales como bandas magnetofónicas, fotografias, diapositivas, colecciones de fotografias digitales, vídeos y películas.

\section{RESULTADOS}

\section{Fuentes}

Se obtuvieron datos en tres categorías: (a) por contribuciones electrónicas, (b) por inspección visual directa y (c) validaciones de expertas y expertos.

\section{Contribuciones electrónicas}

Debido a las particulares condiciones de trabajo y de dispersión geográfica se hizo contacto electrónico con un grupo de 15 investigadores, de los cuales se recibió contribución de nueve de ellos a través de sus propios registros sobre estudios culturales. A continuación se presenta una breve relación de los materiales, los cuales se encuentran en los archivos adjuntos a este informe.

1. Álvaro Rivas - Granada. Del archivo de WANI, Estudios y Publicaciones del CIDCA-UCA, Escrito por Lydia Calero en 2007 y publicado por el CIDCA" en la revista Wani. No. 51 (octubre-diciembre). CIDCA-UCA. Pp. 7.

2. Danilo Salamanca - Managua. El idioma miskito, estado de la lengua y características tipológicas. Pp. 27.

3. Dora María Téllez - Managua. Investigación bibliográfica en la región de la Costa Caribe. URACCAN. 1998. 863 Registros.
4. Elena Benedicto - EEUU. La situación de los estudios lingüísticos en Nicaragua. Integrando Investigación y Comunidad(es). Pp. 25.

5. Georg Grunberg - Austria. Facilita el texto de Robin Schneider: Nicaragua's Atlantic Coast. A Directory of Resources. Pp. 243.

6. Gizanetta Fonseca - De los archivos del CIDCA. Bibliografia de la Costa Caribe de Nicaragua 19902003. Escrito por Lydia Calero et al: WANI, Revista del Caribe Nicaragüense. Octubre-Diciembre 2004 - No. 39.

7. Margarita Vannini-Managua. Proyecto memoria, historia y diversidad cultural de las poblaciones de la Costa Caribe Nicaragüense. 2009. Pp. 15.

8. Mercedes Tinoco-Bilwi. Catálogo de monografias. Biblioteca "Fray Gregorio Smutko" URACCAN. Pp. 47.

9. Mirna Cuninngham - Bilwi. Bibliografia anotada regiones autónomas de la Costa Caribe de Nicaragua. 2009. Pp 424.

Destacan por su perfil los contenidos referidos a temas como: (a) historia, (b) política, (c) cultura, (d) lingüística, (e) catálogos y (f) bibliografias.

\section{Inspección visual directa}

En el trabajo de campo se tuvo acceso a las colecciones institucionales y colecciones personales. En cuanto a las colecciones institucionales destaca la URACCAN con nueve bibliotecas, cinco de carácter general y cuatro especializadas, estás últimas en temas de: (a) autonomía, (b) medicina tradicional, (c) lingüística, (d) recursos naturales.

Se registra en BICU tres bibliotecas de carácter general y dos especializadas, estas dos últimas corresponden a temas de: (a) Investigación y Documentación de la Costa Atlántica y (b) arqueología. Concluye la lista el CADI de la UNAN-Managua que contiene bibliografia especializada en temas de arqueología de la Costa Caribe de Nicaragua.

Se registra bibliografia sobre estudios culturales en dos bibliotecas municipales: Waspam y Bonanza; en el colegio Santa Inés, en Waspam, y en la institución Tininiska, de Bilwi. Cabe destacar que en Waspam se hace sentir el legado del sacerdote capuchino Gregorio Smutko, quien dedicó gran parte de su obra a formar y crear una cultura académica entre la juventud y que se puede apreciar en el marcado interés de sus pobladores por la investigación. 
A continuación se detallan las colecciones institucionales:

Tabla 1: Colecciones institucionales

\begin{tabular}{|l|}
\hline \multicolumn{1}{|c|}{ Colecciones institucionales } \\
\hline 1. Colección Alcaldía - Waspam \\
\hline 2. Colección Biblioteca Municipal - Bonanza \\
\hline 3. Colección BICU - Bilwi \\
\hline 4. Colección BICU - Bluefields \\
\hline 5. Colección BICU - Bonanza \\
\hline 6. Colección BICU-CIDCA - Bluefields \\
\hline 7. Colección BICU-CIDCA Arqueología - Bluefields \\
\hline 8. Colección CADI UNAN Managua \\
\hline 9. Colección Colegio Santa Inés - Waspam \\
\hline 10. Colección IEPA URACCAN - Siuna \\
\hline 11. Colección IMTRADEC URACCAN - Bilwi \\
\hline 12. Colección IPILC URACCAN - Bilwi \\
\hline 13. Colección IREMADES URACCAN - Bilwi \\
\hline 14. Colección Tininiska - Bilwi \\
\hline 15. Colección URACCAN - Bilwi \\
\hline 16. Colección URACCAN - Bluefields \\
\hline 17. Colección URACCAN - Bonanza \\
\hline 18. Colección URACCAN - Rosita \\
\hline 19. Colección URACCAN - Siuna \\
\hline
\end{tabular}

En cuanto a las colecciones personales se tuvo acceso a ellas gracias al apoyo de cada una de las personas que cedieron tiempo y abrieron sus espacios para la realización de los registros fotográficos. Destacan por su valor, la colección de Irene Vidaurre quien es salvaguarda de los manuscritos de Ronald Brocks; y tanto por su abundancia como por los temas abordados destacan las colecciones de Galio Gurdián (138 textos), Bayardo Gámez (73 textos) y Dionisio Melgara (71 textos).

Los temas más relevantes en este conjunto, incluidos los textos de las colecciones con un número menor de ejemplares son: son Autonomía, Educación, Tradiciones y costumbres, Lingüística, Religión, Diccionarios, Medicina tradicional, Literatura, Etnología, Historia, Arqueología, Migraciones, Población indígena y afrodescendiente, Política, Conflicto social, Economía, Cultura y desarrollo, Género, Demografía, Tradición oral.

Algunas colecciones incluyen monografias de licenciaturas y tesis de maestrías y doctorados, en donde predominan los ejemplares

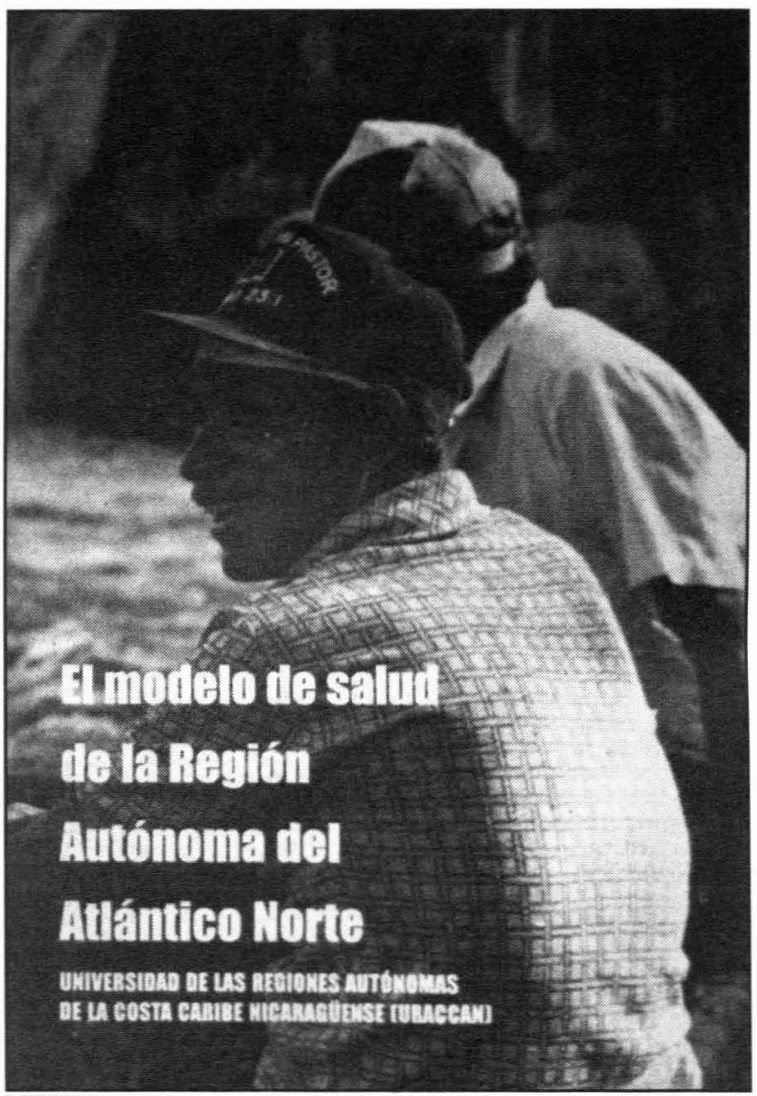

YATAMA LA LUKHA DOR UNA VERDADERA AUTONOMIA EN IA MOSKITIA NICARACUENSE 
propios de cada autor. En este particular es meritorio mencionar las tesis de maestría del programa de Maestría en Antropología Social con mención en Desarrollo Humano realizada en la URACCAN recinto Bilwi (2004-2006) que logró graduar a 30 antropólogas y antropólogos con una meritoria promoción del 100\%.

\section{Validaciones y devolución de los datos de la investigación}

Como parte de los criterios de calidad y validez de la investigación se sometió a dos procedimientos: (a) la solicitud de contribuciones en formatos digitales de documentos y bases de datos, la cual fue respondida por 27 personas con igual número de archivos en la primera fase de la investigación; y (b) la solicitud de validación del informe y base de datos de Excel, la cual fue respondida por 43 personas a través de 64 mensajes.

Algunas opiniones que pueden referirse, se brindan a continuación:

Gilberto López y Rivas del Instituto Nacional de Antropología e Historia de México:

Los resultados, conclusiones, recomendaciones y propuestas resultan de singular importancia para fortalecer los procesos identitarios, socioétnicos
A continuación se detallan las colecciones personales:

Tabla 2: Colecciones personales

\begin{tabular}{|l|}
\hline \multicolumn{1}{|c|}{ Colecciones personales } \\
\hline 1. Colección Adan Silva - Rosita \\
\hline 2. Colección Antonio Mairena - Bilwi \\
\hline 3. Colección Bayardo Gámez - Estelí \\
\hline 4. Colección Betty Rigby y Edwin Taylor - Bilwi \\
\hline 5. Colección Casa Museo - Bilwi \\
\hline 6. Colección Débora Bush y Yuri Zapata - Bilwi \\
\hline 7. Colección Dionisio Melgara - Waspam \\
\hline 8. Colección Edda Moreno - Bilwi \\
\hline 9. Colección Galio Gurdian - Managua \\
\hline 10. Colección Héctor Marley - Bilwi \\
\hline 11. Colección Humberto Lacayo - Waspam \\
\hline 12. Colección Irene Vidaurre - Bluefields \\
\hline 13. Colección María Dolores Álvarez - Managua \\
\hline 14. Colección Maricela Kauffman - Managua \\
\hline 15. Colección Martha Emelda Castro - Bilwi \\
\hline 16. Colección Mercedes Tinoco - Bilwi \\
\hline 17. Colección Mirna Cunningham - Bilwi \\
\hline 18. Colección Pilar Oporta - Waspam \\
\hline
\end{tabular}

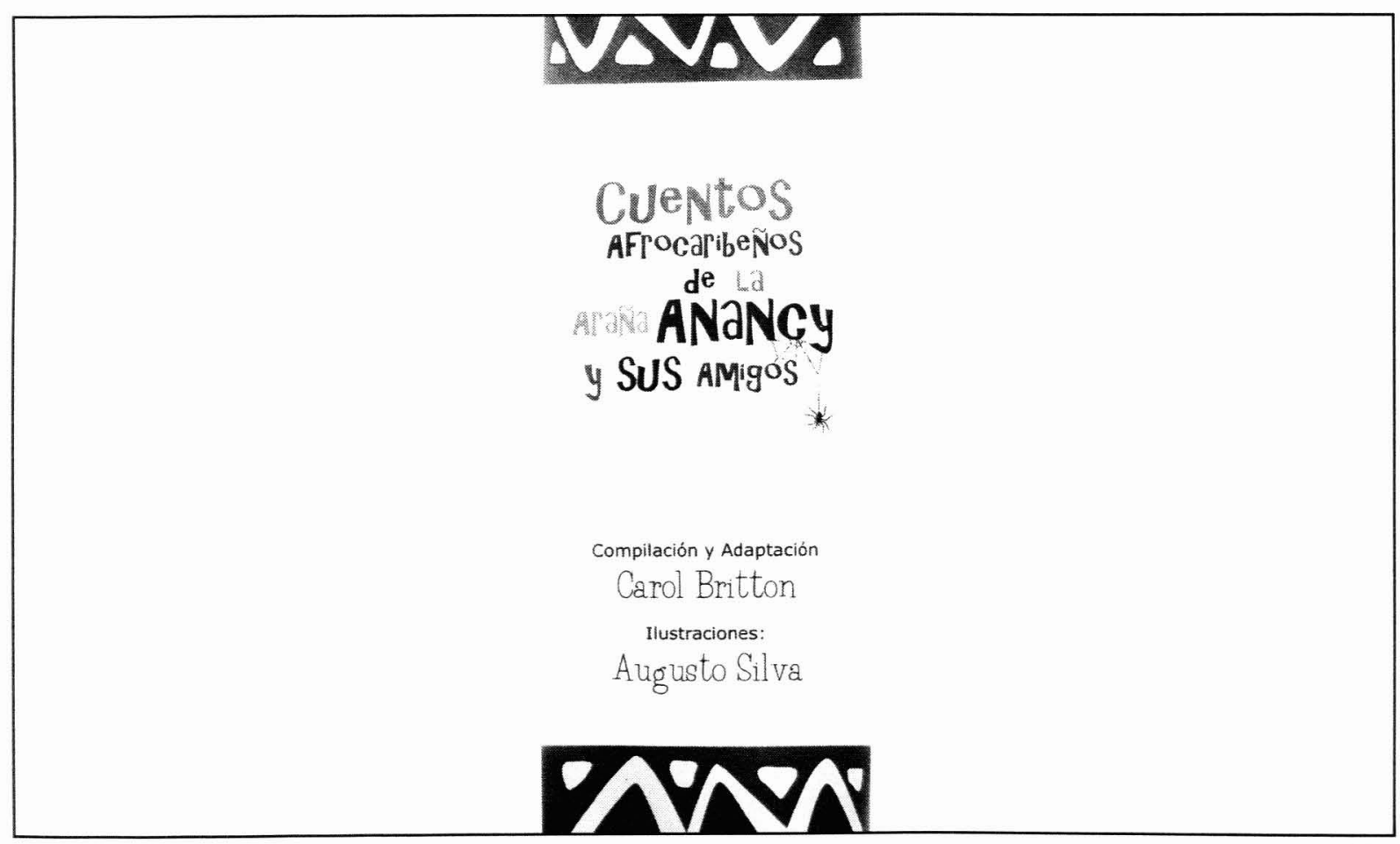


y culturales que dan curso a la autonomía de los pueblos y comunidades de la Costa Caribe. Así mismo, el informe representa una contribución invaluable para quienes desde la academia, las organizaciones sociales, culturales y políticas de dentro y fuera de Nicaragua, han estado y están interesados en acompañar y contribuir a la revitalización creativa y cultural de los pueblos de la Costa Caribe de ese país ( 20 noviembre 2020 ).

Georg Grünberg, Instituto de América Latina y Universidad de Viena:

Es un trabajo muy bien estructurado y de gran utilidad, destacándose el registro de las colecciones personales, tan importantes y tan dificiles de accesar (20 noviembre 2010).

Claribel Castillo, Vice-Rectora URACCA Nueva Guinea:

Me parece un documento valioso y las recomendaciones son insumos muy importantes para que las universidades podamos ampliar nuestros temas de investigación (30 noviembre 2010).

Dolores Figueroa, Universidad de York:

Encuentro muy atinado dar cuenta del estado físico del acervo bibliográfico institucional y personal. Dan pena las pocas condiciones que hay en la región para preservar material escrito y promover la lectura y el uso de esos materiales. Es un mapeo extenso (12 noviembre 2020).

Eugenia Ibarra, Universidad de Costa Rica:

Es un trabajo de una envergadura profunda y amplia, necesaria, indispensable. Llena lagunas de información que tenemos los investigadores que nos interesamos en la Costa Caribe de Nicaragua. No solo ayudará a los investigadores, profesores, docentes, entre algunos, como también a algunos miembros de comunidades indígenas. Representa un paso esencial hacia la salvaguarda de sus culturas (23 noviembre 2010).

Gabriel Ascencio, Universidad Nacional Autónoma de México - Programa de Investigaciones Multidisciplinarias sobe Mesoamérica y el Sureste (PROIMMSE) - Instituto de Investigaciones Antropológicas:

La investigación realizada ayuda a identificar aspectos problemáticos que resolver para hacer accesible el conocimiento existente, también ayuda a precisar los énfasis en que se ha concentrado la investigación y cuáles deben promoverse para reparar algunas lagunas pero se expresan de forma muy general, además precisa las obras, que por ser fundamentales deben traducirse al español (24 noviembre 2010).

Marcos Guevara, Universidad de Costa Rica:

La Costa Caribe de Nicaragua ha sido, indudablemente, una de las áreas de América Central histórica y geopolíticamente más dinámicos, nicho de múltiples eventos de importancia regional, continental y hasta mundial. Por ello es sabido que existen muchos estudios, aunque una gran cantidad de ellos se haya generado desde centros académicos, instituciones e intereses particulares fuera de la misma Costa Caribe, de ahí la necesidad de iniciar este inventario ( 2 diciembre 2010).

María Eugenia Bozzoli, Universidad de Costa Rica:

Se trata de un trabajo necesario, útil para estudiosos y para la población a la que se aplican estos conocimientos. Representa un esfuerzo conducente a acciones importantes de seguimiento tanto de parte de eruditos en los distintos temas abarcados por estos estudios como para las comunidades locales involucradas. Fue importante abarcar las colecciones personales, porque éstas no suelen aparecer a menudo en las listas de acervos bibliográficos y documentales. Los párrafos sobre preocupaciones y necesidades expresadas desde ambos tipos de fuentes son una guía para acciones posteriores dedicadas a la salvaguarda de colecciones (21 noviembre 2010).

Morna McLeod, Universidad de Columbia Británica:

Me parece un trabajo muy serio y bien presentado. Tengo sólo algunos comentarios y sugerencias: (1) De cara al futuro, negociar -como condición- que quienes investiguen de fuera devuelvan algo en español (un artículo, una síntesis de sus libros y capítulos, etc.) y que hagan devoluciones accesibles en power point en algunas instituciones en la Costa Caribe. (2) Hacer convenios con diferentes universidades costeñas para promover no sólo el estudio, sino la investigación colaborativa y otras formas de colaboración en relación con los estudios culturales. Esto podría pensar, por ejemplo, con las áreas de Estudios Latinoamericanos de la UNAM (México), de la Universidad de Texas 
(Austin), etc., y que se promuevan intercambios de estudiantes (extranjeros/as y de la Costa Caribe al extranjero) que trabajen sobre estos temas. (3) En Propuestas y visión de los estudios culturales (p.12), no entiendo porque quieren unificar criterios con relación a los argumentos de las y los investigadores, pues la diversidad de opiniones y abordajes da lugar a una mayor riqueza y puntos de diferencia y además de comparación de análisis (28 noviembre 2010 ).

Salvador García (Lole), Antropólogo nicaragüenseargentino:

Uno de los mayores retos que se impone a la sistematización de los estudios culturales (y sobre todo con vistas a aportar a la producción científica en Nicaragua), no pasa únicamente por organizar todo lo que se ha escrito, ficharlo y ponerlo al alcance de la mayor cantidad de gente, sino también por ponderar esa misma producción a fin de evaluar avances, historizar recorridos, visibilizar omisiones y denunciar las contradicciones y desfasajes que existen en la producción de conocimiento en general. Nicaragua, y más aun La Costa, forma parte de la periferia de la periferia, lo que implica entre otras cosas, que es el campo de operaciones de muchas universidades del mundo sin que se genere un conocimiento integral, sistemático y medianamente coherentes. Es decir, creo que hace falta un plus de esfuerzo por organizar los relatos, las interpretaciones, las formas de trabajo, los datos y especialmente, los supuestos teóricos que maneja cada investigador para llegar a las conclusiones que llega. Si no, parece que sólo por el hecho de haberse publicado es una verdad inamovible y no una construcción académica en algún punto atravesado por subjetividades, modas académicas, discusiones entre escuelas y paradigmas de época (21 diciembre 2010).

En general valoran la importancia del estudio y la abundancia de datos. Treinta y cinco personas brindaron nuevos datos como nuevas bibliografias de su producción personal y nuevos enlaces a páginas y sitios de bibliotecas a nivel mundial. Se recibieron aportes para la delimitación de los textos los cuales se recomienda (a) curar y publicar, (b) reimprimir, (c) traducir e imprimir.

Las opiniones de personas expertas consultadas confirman la importancia del estudio, la utilidad y necesidad que existe para que se divulguen los resultados, y aportan con diferentes propuestas para enriquecer la sistematización con vistas al futuro.

Las propuestas más significativas se encuentran alrededor de la necesidad de promover la investigación en temas culturales, divulgar las bases de datos, abrir el acceso de los materiales a toda la población, mejorar las condiciones de las bibliotecas y enriquecerlas con nuevos ejemplares que se han encontrado en las colecciones personales.

\section{Colecciones encontradas}

Las colecciones encontradas, como ya se ha hecho referencia, son 37. Durante el levantado de datos se tomaron fotografias de las portadas de los libros, del pie de imprenta y ocasionalmente de los textos, sobretodo en materiales que se encontraron en grave situación de deterioro. En aquellos lugares en donde obtuvimos el permiso correspondiente tomamos fotografías de los contextos, los cuales permiten dar evidencia del estado en que se encuentran resguardados los materiales. En total se han registrado 1,302 libros, 1,893 documentos y artículos científicos contenidos en revistas, lo que suman 3,195 registros. A continuación se brinda el detalle:

Las personas entrevistadas afirman que han construido con gran esfuerzo sus colecciones personales -bibliográficas, documentales, hemerográficas, fotográficas $\mathrm{y}$, ocasionalmente, obras propias. $\mathrm{Al}$ respecto refieren: (a) alto costo de los libros, (b) no desean donar sus libros a las bibliotecas, (c) no existen lugares adecuados para la conservación y protección de los materiales, (d) las investigaciones de tipo tesis y monografias no se publican en forma de libros accesibles a la población, (e) las investigaciones académicas no siempre conllevan una devolución sistemática de los textos a las poblaciones con quienes se hicieron los trabajos, (f) falta de confianza de quienes portan y salvaguardan textos originales para acceder a que las obras sean curadas y publicadas, (g) falta de confianza de quienes escriben en cuanto a la aplicación de las leyes de derechos de autor.

Las personas encargadas directamente de las bibliotecas y centros de documentación consideran que (a) las bibliotecas requieren de una mayor inversión en adquisición de libros, (b) las bibliotecas son multiusos en tanto prestan servicios a toda la población universitaria, escolar y población en general, y cumplen diversas funciones, incluso como salas de eventos, (c) las bibliotecas atienden todos los temas en un mismo espacio con un personal reducido, (d) se ha disminuido el hábito de lectura en la sociedad, (e) los textos 
Tabla 3: Colecciones de libros

\begin{tabular}{|c|c|c|c|c|}
\hline Colecciones & (Wibros & $\begin{array}{l}\text { Prede } \\
\text { ymprenta } \\
\text { y textos }\end{array}$ & Contexto & Tola1 \\
\hline 1. Colección Adan Silva - Rosita & 11 & 35 & 14 & 60 \\
\hline 2. Colección Alcaldía - Waspam & 7 & 2 & 2 & 11 \\
\hline 3. Colección Antonio Mairena - Bilwi & 4 & 10 & 0 & 14 \\
\hline 4. Colección Bayardo Gámez - Estelí & 73 & 1 & 0 & 74 \\
\hline 5. Colección Betty Rigby y Edwin Taylor & 28 & 24 & 17 & 69 \\
\hline 6. Colección Biblioteca Municipal - Bonanza & 23 & 42 & 0 & 65 \\
\hline 7. Colección BICU - Bilwi & 60 & 43 & 26 & 129 \\
\hline 8. Colección BICU - Bluefields & 40 & 38 & 6 & 84 \\
\hline 9. Colección BICU - Bonanza & 13 & 17 & 0 & 30 \\
\hline 10. Colección CADI UNAN Managua & 16 & 0 & 0 & 16 \\
\hline 11. Colección Casa Museo - Bilwi & 8 & 0 & 0 & 8 \\
\hline 12. Colección BICU-CIDCA - Bluefields & 55 & 30 & 20 & 105 \\
\hline 13. Colección BICU-CIDCA Arqueología - Bluefields & 0 & 0 & 67 & 67 \\
\hline 14. Colección Colegio Santa Inés - Waspam & 6 & 27 & 7 & 40 \\
\hline 15. Colección Débora Bush y Yuri Zapata & 23 & 0 & 4 & 27 \\
\hline 16. Colección Dionisio Melgara - Wapam & 71 & 108 & 33 & 212 \\
\hline 17. Colección Edda Moreno - Bilwi & 2 & 28 & 0 & 30 \\
\hline 18. Colección Galio Gurdian - Managua & 138 & 298 & 0 & 436 \\
\hline 19. Colección Héctor Marley - Bilwi & 11 & 13 & 0 & 24 \\
\hline 20. Colección Humberto Lacayo - Waspam & 6 & 15 & 0 & 21 \\
\hline 21. Colección IEPA URACCAN - Siuna & 43 & 25 & 0 & 68 \\
\hline 22. Colección IMTRADEC URACCAN - Bilwi & 133 & 9 & 12 & 154 \\
\hline 23. Colección IPILC URACCAN - Bilwi & 0 & 0 & 2 & 2 \\
\hline 24. Colección IREMADES URACCAN - Bilwi & 3 & 1 & 0 & 4 \\
\hline 25. Colección Irene Vidaurre - Bluefields & 10 & 0 & 3 & 13 \\
\hline 26. Colección María Dolores Álvarez - Managua & 9 & 0 & 0 & 9 \\
\hline 27. Colección Maricela Kauffman - Managua & 18 & 41 & 0 & 59 \\
\hline 28. Colección Martha Emelda Castro - Bilwi & 50 & 11 & 0 & 61 \\
\hline 29. Colección Mercedes Tinoco - Bilwi & 23 & 102 & 2 & 127 \\
\hline 30. Colección Mirna Cunningham - Bilwi & 0 & 0 & 20 & 20 \\
\hline 31. Colección Pilar Oporta - Waspam & 5 & 35 & 3 & 43 \\
\hline 32. Colección Tininiska - Bilwi & 10 & 20 & 4 & 34 \\
\hline 33. Colección URACCAN - Bilwi & 92 & 24 & 8 & 124 \\
\hline 34. Colección URACCAN - Bluefields & 136 & 165 & 21 & 322 \\
\hline 35. Colección URACCAN - Bonanza & 57 & 41 & 0 & 98 \\
\hline 36. Colección URACCAN - Rosita & 36 & 49 & 6 & 91 \\
\hline \multirow[t]{2}{*}{ 37. Colección URACCAN - Siuna } & 82 & 37 & 0 & 119 \\
\hline & 1302 & 1291 & 277 & 2870 \\
\hline Sub total & & & & \\
\hline
\end{tabular}


escritos en idiomas extranjeros son poco consultados, (f) los textos referidos a las culturas indígenas o afrodescendientes no necesariamente contienen las traducciones, (g) temas relevantes de la tradición oral y de las historias locales requieren de investigaciones académicas con calidad para ser publicadas, (h) colecciones especiales no se promueven, por ejemplo, la colección-biblioteca personal del escritor Lizandro Chávez Alfaro, (i) poca promoción de lectura pública.

\section{Entrevistas}

Las 68 personas consultadas residen: 24 en Bilwi, 12 en Bluefields, siete en Managua, cinco en Bonanza, seis en Waspam, tres en Rosita, cuatro en otros (Canadá, Austria y Estados Unidos), dos en Siuna, uno en Granada, dos en Nueva Guinea, uno en Estelí y uno en San Marcos.

Tabla 4: Documentos y artículos cientifico

\begin{tabular}{|l|c|c|c|c|}
\hline \multicolumn{1}{|c|}{ Colecciones electrónicas y revistas } & Libros & $\begin{array}{c}\text { Pie de } \\
\text { Imprenta } \\
\text { y textos }\end{array}$ & Contexto & Total \\
\hline Colección Dora María Téllez & 863 & 0 & 0 & 863 \\
\hline Colección Elena Benedicto & 308 & & & 308 \\
\hline Colección Danilo Salamanca & 48 & & & 48 \\
\hline Colección WANI & 312 & 0 & 0 & 312 \\
\hline Colección BNBD (volúmenes) & 4 & 0 & 0 & 4 \\
\hline Colección Tininiska & 308 & 0 & 0 & 308 \\
\hline Colección Autonomía (periódico) & 50 & 0 & 0 & 50 \\
\hline Sub total & 1893 & & & 1893 \\
\hline Total & & & & \\
\hline
\end{tabular}

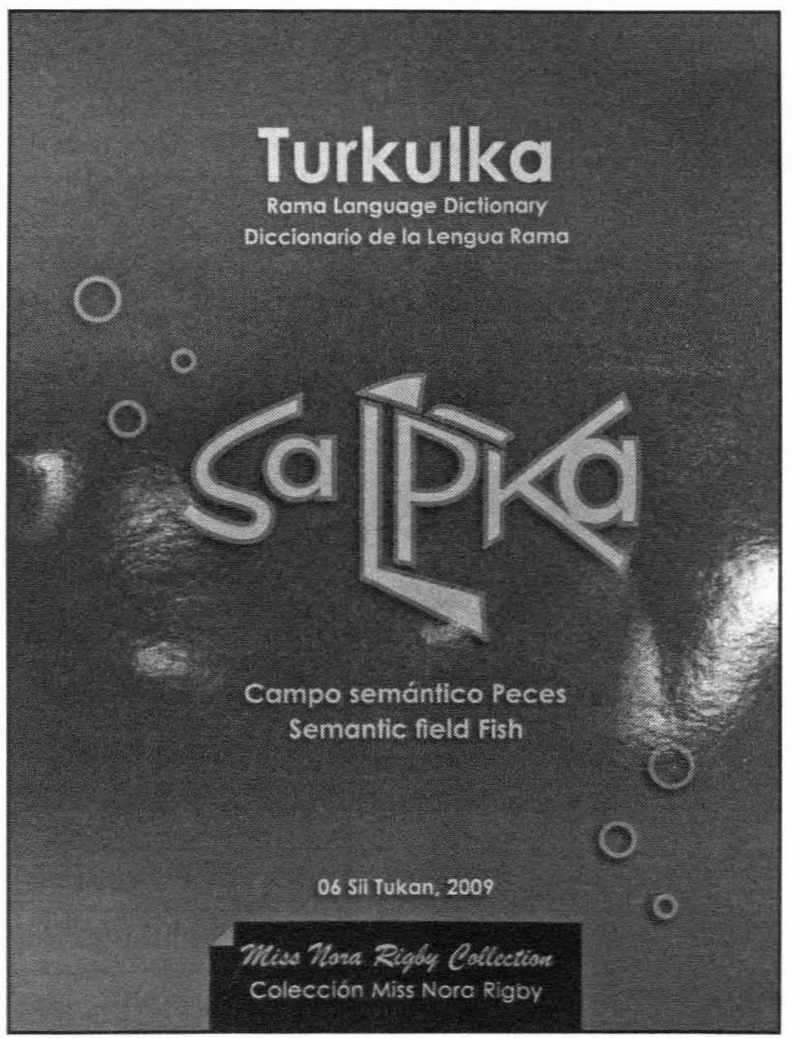


Tabla 5: Personas entrevistadas y lugar de residencia

\begin{tabular}{|c|c|}
\hline Nombre & Ciudad \\
\hline 1. Adela Williams & Bilwi \\
\hline 2. Albert StClair & Bilwi \\
\hline 3. Álvaro Rivas & Granada \\
\hline 4. Avelino Cox & Bilwi \\
\hline 5. Bayardo Gámez & Estelí \\
\hline 6. Betty Rigby & Bilwi \\
\hline 7. Brooklin Rivera & Bilwi \\
\hline 8. Carlos Eddy & Bluefields \\
\hline 9. Danilo Salamanca & Managua \\
\hline 10. Débora Bush & Bilwi \\
\hline 11. Denis Mairena & Bilwi \\
\hline 12. Dionisio Melgara & Waspam \\
\hline 13. Dolores Figueroa & Toronto \\
\hline 14. Dominga Zeledón Palacios & Siuna \\
\hline 15. Dora María Téllez & Managua \\
\hline 16. Edda Moreno & Bilwi \\
\hline 17. Edwin Taylor & Bilwi \\
\hline 18. Elena Benedicto & EEUU \\
\hline 19. Eugenio López & Nueva Guinea \\
\hline 20. Fernando Saavedra & Bilwi \\
\hline 21. Fidel Wilson & Bilwi \\
\hline 22. Floriano Vargas & Waspam \\
\hline 23. Galio Gurdián & Managua \\
\hline 24. Germán Castellón & Bonanza \\
\hline 25. German Romero & San Marcos \\
\hline 26. Gustavo castro & Bluefields \\
\hline 27. Gizanetta Fonseca & Managua \\
\hline 28. Héctor Marley & Bilwi \\
\hline 29. Hugo Sujo & Bluefields \\
\hline 30. Humberto Lacayo & Waspam \\
\hline 31. Indiana Diesen & Bilwi \\
\hline 32. Irene Vidaurre & Bluefields \\
\hline 33. Jenny Ruiz & Rosita \\
\hline 34. Jorge Eduardo Arellano & Managua \\
\hline
\end{tabular}

\begin{tabular}{|c|c|}
\hline 35. Jorge Grunberg & Viena \\
\hline 36. José Antonio Mairena & Bonanza \\
\hline 37. Juliana Francis & Nueva Guinea \\
\hline 38. Katy Schiele & Waspam \\
\hline 39. Loyda Stamp & Bilwi \\
\hline 40. Margarita Vanini & Managua \\
\hline 41. Maricela Kauffman & Managua \\
\hline 42. Mark Queen & Bluefields \\
\hline 43. Martha Emelda Castro & Bilwi \\
\hline 44. Melba Joiner & Bluefields \\
\hline 45. Melba McLean & Bilwi \\
\hline 46. Melvin James & $\begin{array}{l}\text { Bluefields/Kar- } \\
\text { awala }\end{array}$ \\
\hline 47. Mercedes Tinoco & Bilwi \\
\hline 48. Miguel Gonzáles & Toronto \\
\hline 49. Milton Zamora & Bilwi \\
\hline 50. Mirna Cuninngham & Bilwi \\
\hline 51. Olga Taylor & Bluefields \\
\hline 52. Pedro Chavarría & Bluefields \\
\hline 53. Petrona Rosales & Bonanza \\
\hline 54. Pilar Oporta & Waspam \\
\hline 55. Pio Alejandro García & Siuna \\
\hline 56. Rayfield Hodgson & Bluefields \\
\hline 57. Reyna Aracelly García & Bilwi \\
\hline 58. Rosa Cunningham & Bilwi \\
\hline 59. Rosa Kowalski & Waspam \\
\hline 60. Santos Hernández & Rosita \\
\hline 61. Sasha Marley & Bilwi \\
\hline 62. Tomas Quijano Maradiaga & Bonanza \\
\hline 63. Valeriano Antolín & Bilwi \\
\hline 64. Verónica Valdivia & Rosita \\
\hline 65. Víctor Obando & Bluefields \\
\hline 66. Violeta Soza Castillo & Bluefields \\
\hline 67. Yuri Zapata & Bilwi \\
\hline 68. Zenia López Maradiaga & Bonanza \\
\hline
\end{tabular}


Tabla 6: Personas entrevistadas

\begin{tabular}{|l|c|}
\hline \multicolumn{1}{|c|}{ Lugar } & Personas entrevistadas \\
\hline Bluefields & 12 \\
\hline Bilwi & 24 \\
\hline Bonanza & 5 \\
\hline Estelí & 1 \\
\hline USA & 1 \\
\hline Granada & 1 \\
\hline Managua & 7 \\
\hline Nueva Guinea & 2 \\
\hline Rosita & 3 \\
\hline Siuna & 2 \\
\hline San Marcos & 1 \\
\hline Toronto & 2 \\
\hline Viena & 1 \\
\hline Waspam & 6 \\
\hline & 68 \\
\hline
\end{tabular}

Como se puede observar, la mayor parte de las entrevistas se realizaron, en orden descendente, en Bilwi, Bluefields y Managua; en segundo plano quedan Las Minas -Rosita, Bonanza y Siuna- y Nueva Guinea. El dato genera algunas hipótesis que pueden continuarse evaluando, entre ellas, (a) la significativa presencia indígena en la Región Autónoma del Atlántico Norte es motivo para la realización de numerosas investigaciones externas e internas, cuya tradición arranca desde los viajeros, etnógrafos, lingüistas, y que ahora se articulan en procesos conjuntos con centros de investigación en comunidades académicas nacionales y extranjeras; (b) la significativa presencia afrodescendiente en la Región Autónoma del Atlántico Sur es motivo para la realización de investigaciones externas e internas, las cuales requieren de una mayor y más vigorosa articulación con quienes estudian el tema de la diáspora y de la integración cultural negra; (c) los estudios culturales sobre la población mestiza costeña-segunda y tercera generación, por lo menos, y mestiza reciente son muy escasas; (d) el acceso a la educación formal de las poblaciones indígenas ha sido más lento que en el caso de las poblaciones afrodescendientes, mestizas costeñas, y mestizas recientes; (e) minorías como la población china y china-negra son poco abordadas; (f) la existencia real de una pirámide cultural, con variaciones locales, limita y eventualmente entra en contradicción con las posibilidades de continuidad, desarrollo y reafirmación de las culturas indígenas, afrodescendientes y mestizas costeñas,

\section{Almacenamiento y estado general de las colecciones}

En los contenidos de las carpetas se incluyen fotografías de los contextos. En este sentido es necesario poner en evidencia que existen distintos modelos de almacenamiento, los cuales examinaremos con base en las evidencias.

Caso 1: Biblioteca personal Casa Museo. Los materiales se encuentran organizados en archivadores profesionales, están rotulados indicando su contenido y se ubican en estantes de madera de uso exclusivo para los materiales, entre los que predominan documentos. En otros casos, los documentos se encuentran cuidadosamente archivados y clasificados en contenedores plásticos con sistema de cerrado hermético. También se puede apreciar que los materiales están en proceso de clasificación para su ubicación definitiva.
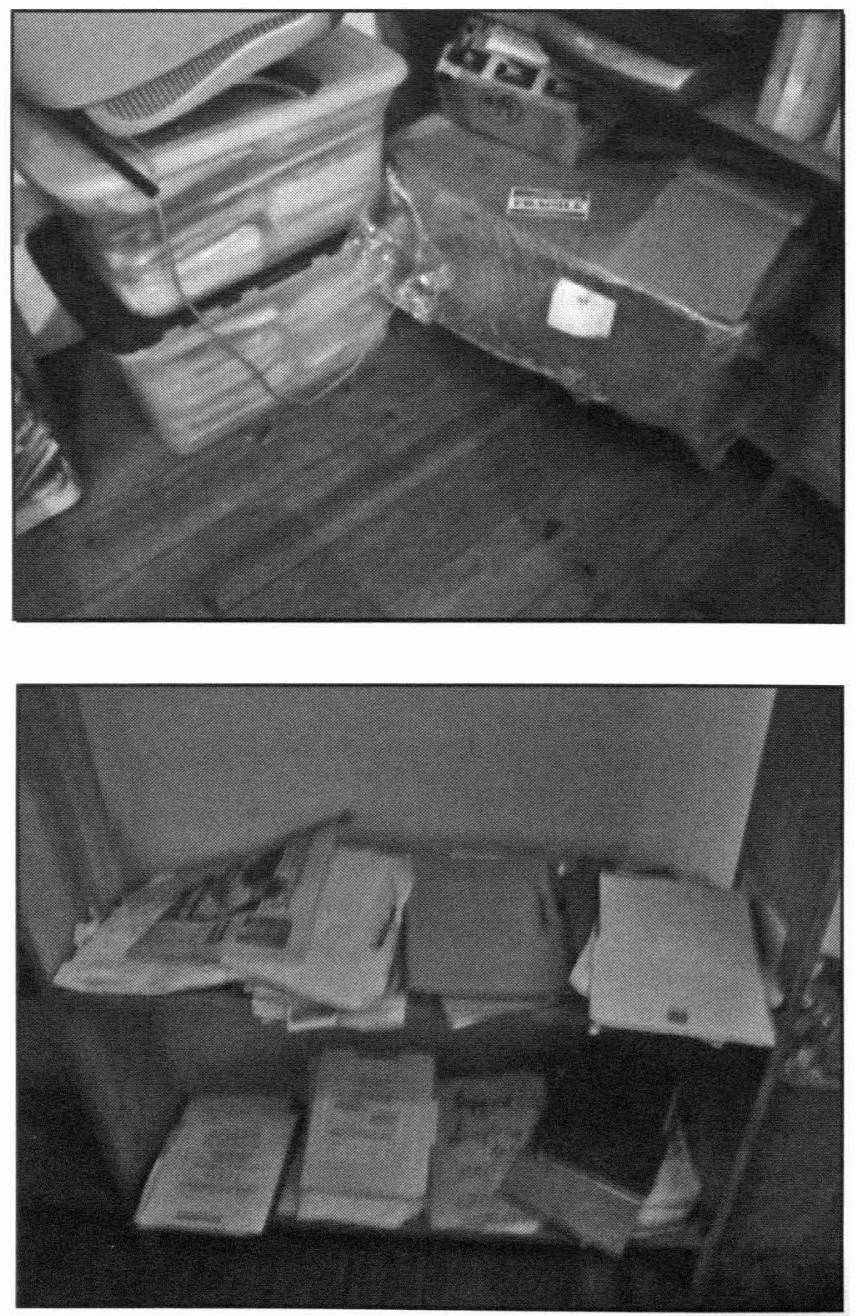


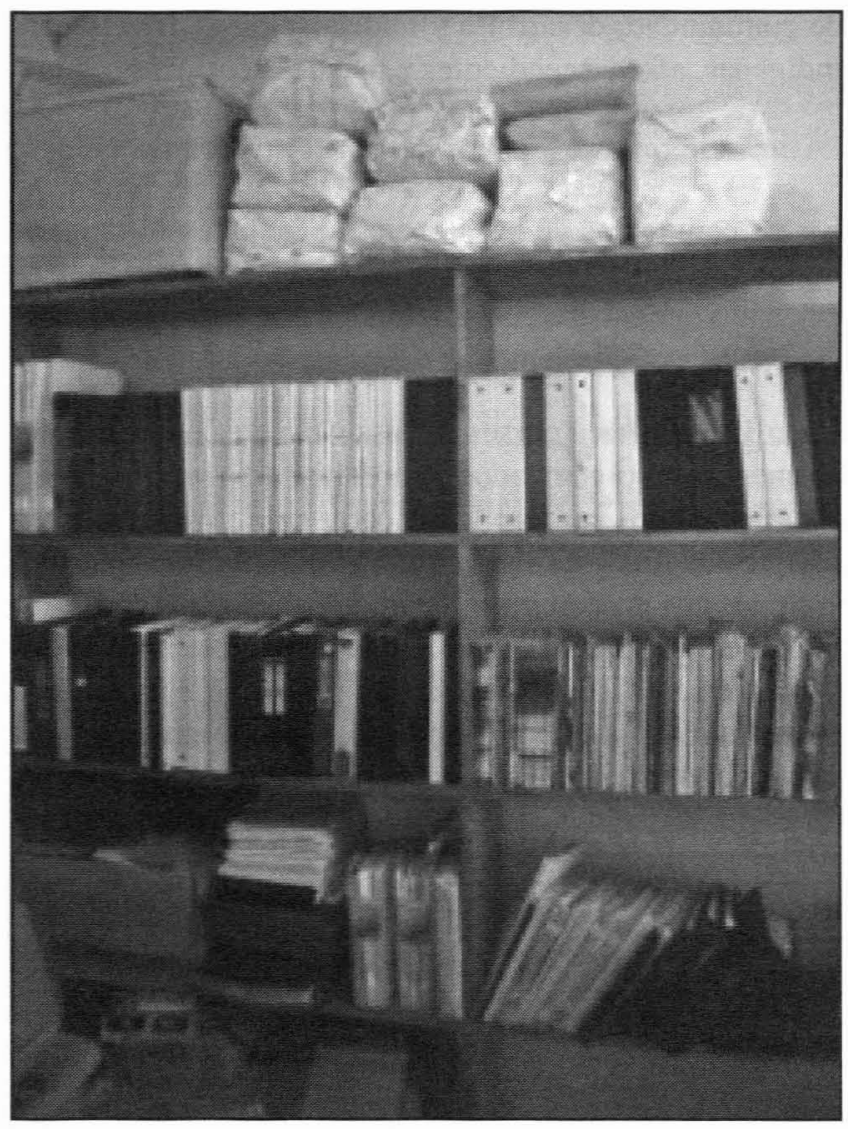

Caso 2: Biblioteca personal de Betty Rigby y Edwin Taylor. El paso de huracanes en los años precedentes llevó a los propietarios de esta colección a buscar un almacenamiento seguro, el cual consiste en contendores de cartón parafinado con sello hermético, sin embargo, no todos los documentos encontraron un espacio en los contenedores y, por tanto, se mojaron durante las lluvias, lo que lleva a sus propietarios a extenderlos para secarlos.

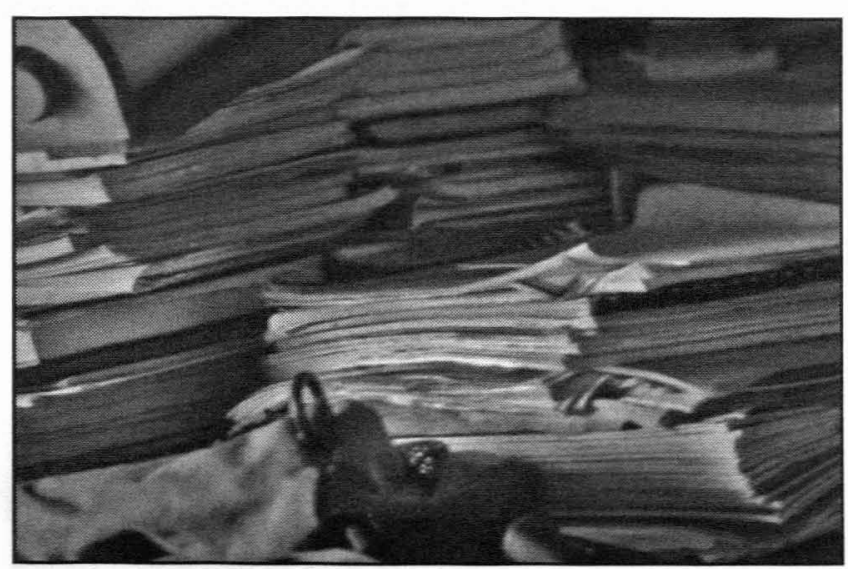

Caso 3: Biblioteca y Centro de Documentación CIDCABilwi. En este espacio se encontró la mayor colección hemerográfica, sin embargo, su estado de conservación es sumamente vulnerable; los materiales se encentran expuestos a la intemperie bajo techo, lo que significa polillas, polvo, hongos y humedad. En cuanto a la sección de libros, las condiciones son mejores, sin embargo, no existe un sistema de archivos y ficheros que permita una búsqueda de materiales por temas. Este centro puede elevar su calidad con un rápido y eficaz tratamiento de sus colecciones y sistema de organización general. Por otra parte, el hecho de resguardar es una garantí de conservación, pero no facilitan el acceso a los materiales.
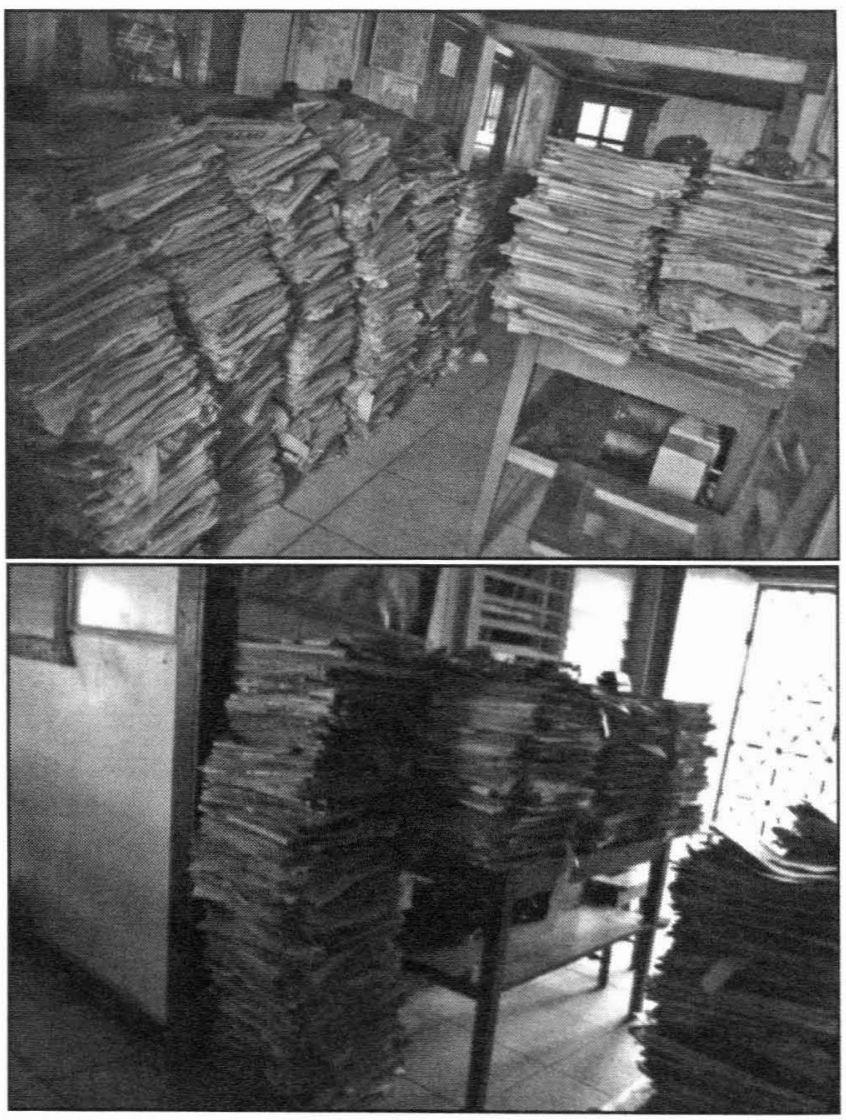

Caso 4. Colección BICU-CIDCA Bluefields: En este caso encontramos que en los materiales, mayoritariamente hemerográficos han sido colocados en bolsas plásticas a partir de una clasificación inicial. Sin embargo podemos observar que hay materiales muy valiosos, sobre todo por su antigüedad, entre 80 y 100 años, que se encuentran en malas condiciones y requieren de una atención inmediata. 


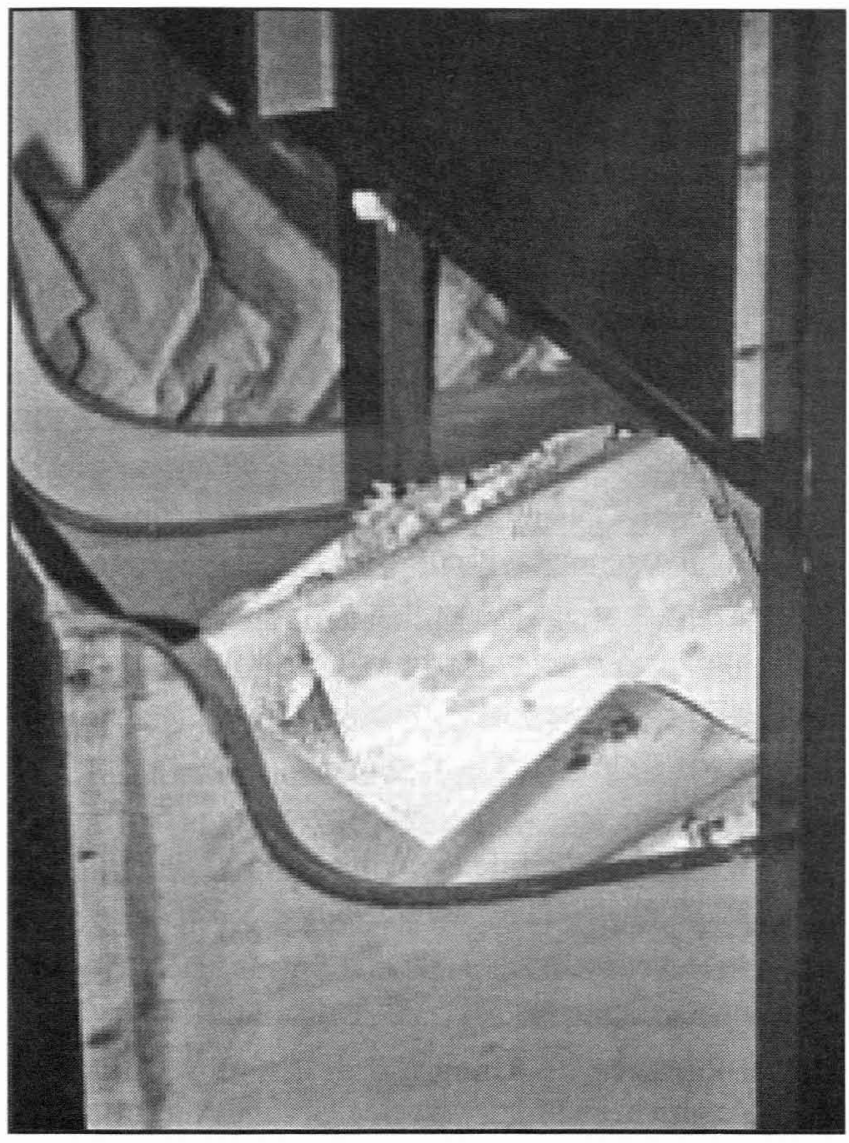

Caso 5: Colección IMTRADEC-URACCAN-Bilwi. Esta colección es la más abundante en ejemplares especializados en estudios culturales con énfasis en Salud y Medicina tradicional. Se encuentra en muy buenas condiciones de protección y un excelente sistema de organización de las bases de datos, clasificación y uso selectivo de estanterías. Esta colección es susceptible de mejorar a corto plazo, con lo que se eleva su calidad de punto de referencia especializado en estudios culturales.

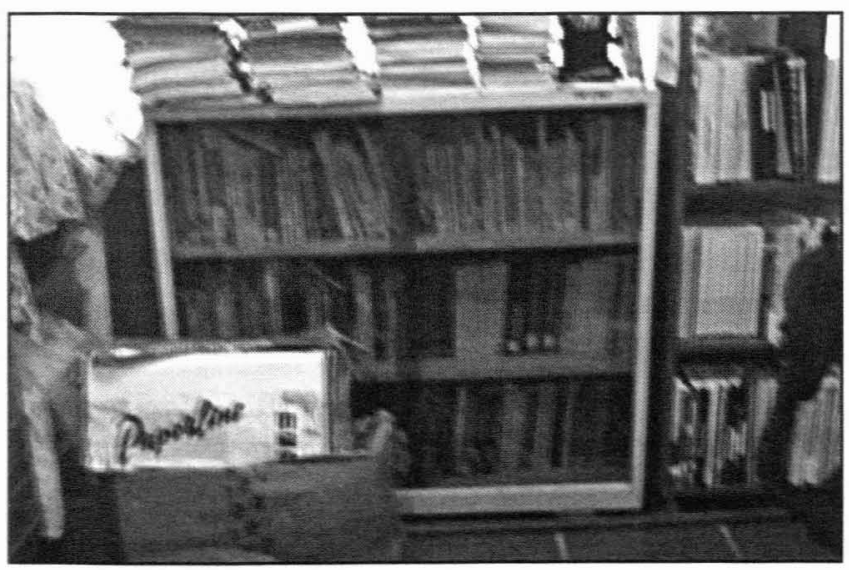

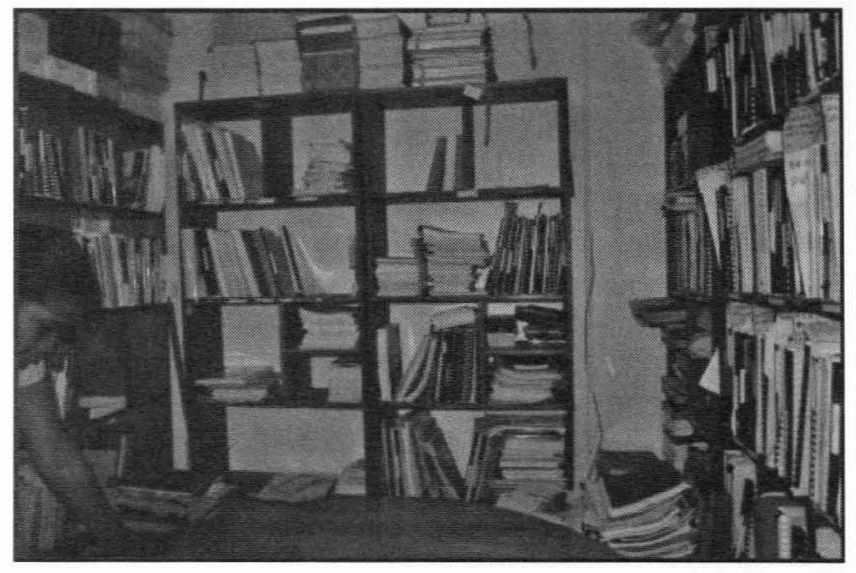

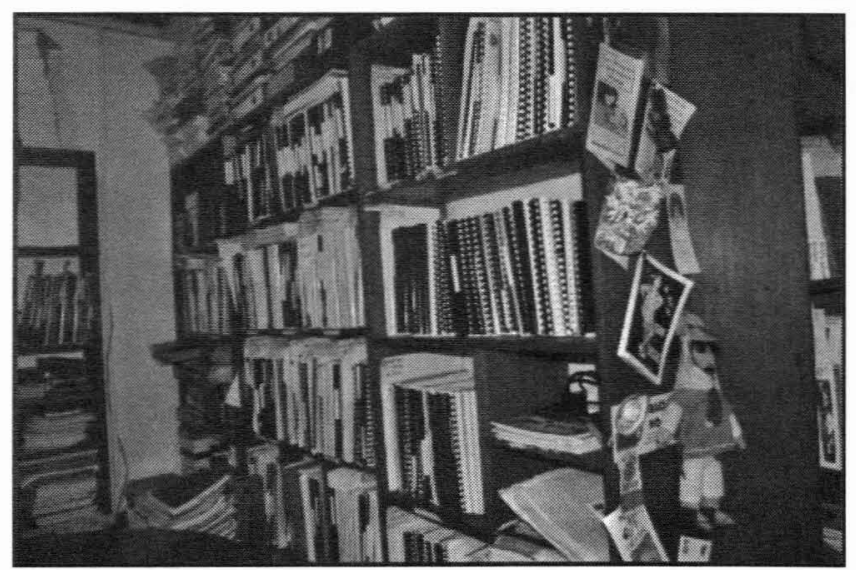

Caso 6: Colección URACCAN-Bluefields y URACCANBilwi. Ambos centros se localizan en un edificios cuya construcción es adecuada tanto para los libros y materiales como para las/los lectores. Goza de amplias salas con mesas adecuadas. En el caso de Bluefields cuenta con un centro especializado, que es la Colección Lizandro Chávez Alfaro.

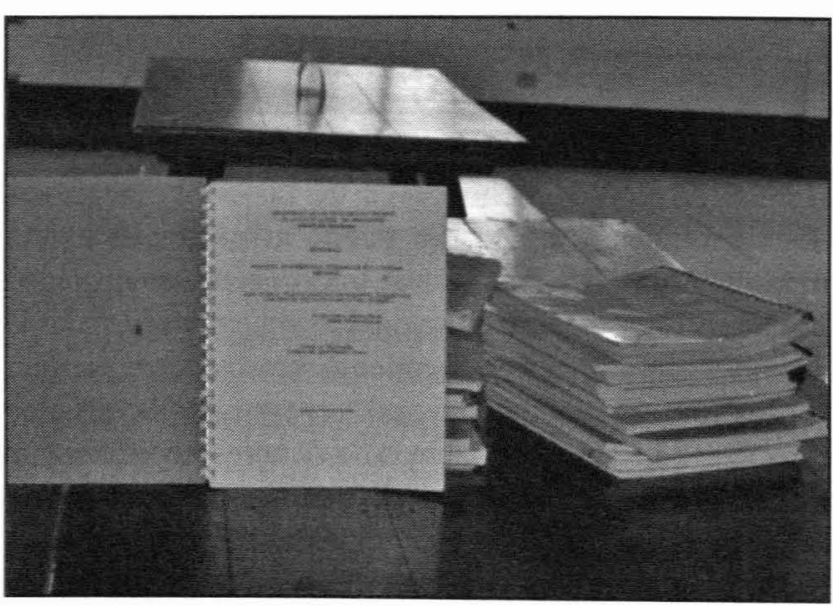


Caso 8: Colección BICU-Bilwi. El espacio destinado a la biblioteca se encuentra en segundo piso del edificio principal. Cuenta con una breve sala de lectura, un pequeño cubículo para el acceso a internet y el espacio principal está utilizado por las estanterías de libros. La sección con mayor cantidad de estudios culturales es la referida a las monografías y proyectos de investigación académica. Otros textos específicos de estudios culturales se encuentran dispersos en los estantes de Ciencias Sociales y del área de Educación.
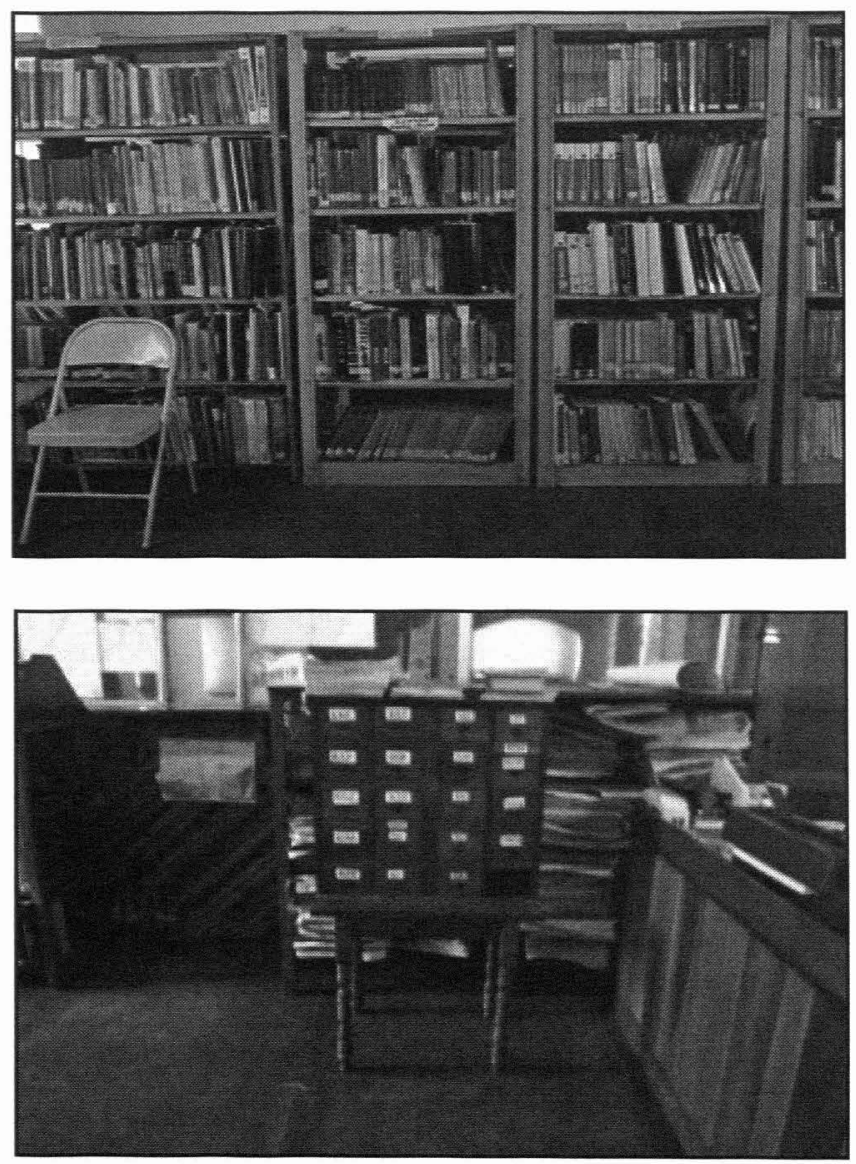

Hemos observado ocho casos de las 37 colecciones documentadas (21.6\%). Se puede afirmar que existe tratamiento de los materiales, tanto en las colecciones privadas como en las institucionales, sin embargo, todavía no son de amplio aprovechamiento, básicamente porque: (a) los libros y documentos no tienen espacios propios especializados, (b) los sistemas de ficheros no utilizan un mismo sistema de clasificación, (c) no hay intercambio de bases de datos entre las colecciones y (d) no se publican boletines que informen de manera regular y sistemática sobre las existencias y adquisiciones de cada centro.

\section{Instituciones académicas, culturales y de investigación}

Durante el proceso de investigación se encontró 43 sitios electrónicos, necesarios para ingresar a otros recursos bibliográficos. Los más relevantes son:

1. Archivo de Simancas en Vallodolid, España, en http://www.mcu.es/archivos/MC/AGS/index.html

2. Archivo General de Centroamérica. Biblioteca Nacional, Ciudad Guatemala, en: http://www. archivogeneraldecentroamerica.com/

3. Archivo General de la Nación AGN - http://www. archivogeneral.gov.co/

4. Archivo Histórico Militar en Madrid, España, en http://censoarchivos.mcu.es/CensoGuia/portada.htm

5. Archivo Nacional de Costa Rica ANCR - http:// www.archivonacional.go.cr/

6. Archivo Naval en Madrid, España, en http:// www.armada.mde.es/ArmadaPortal/page/Portal/ armadaEspannola/ inicio home/

7. Archivos de Indias de Sevilla España, en http://www. mcu.es/archivos/MC/AGI/index.html

8. Biblioteca del Congreso de Estados Unidos de América, en http://www.loc.gov/index.html

9. Biblioteca Luis Ángel Arango - http://www. banrepcultural.org/blaa

10. Biblioteca Nacional - http://www.sinabi.go.cr/

11. Cambridge University Press - Referencia “América", en http://www.cambridge.org/americas/

12. Center for Latin American and Caribbean StudiesReferencia a Jeffrey Gould. http://www.indiana. edu/ histweb/

13. Centro de servicios para las organizaciones no gubernamentales finlandesas dedicadas al trabajo de cooperación para el desarrollo (KEPA) Referencia a programa de Fortalecimiento de la Educación Intercultural Bilingüe de la Costa Atlántica (FOREIBCA). http://www.kepa.fi/ uutiset/3941

14. El Servicio de Belice Biblioteca Nacional y Sistema de Información Instituto de Jamaica en Kingston, en http://www.nlsbze.bz/

15. Endangered Language Fund - Referencia a Jane Freeland. http://www.endangeredlanguagefund.org/

16. Enlace Académico Centroamericano - Referencia a Dora María Téllez y Andira Watson. Revista WANI 
http://www.enlaceacademico.org/base-documental/ revista-wani/;

17. Enlace Académico Centroamericano - Referencia a Margarita Vanini. Memoria Centroamericana http:// mc.enlaceacademico.org/

18. Fondo de asistencia internacional de los estudiantes y académicos noruegos (SAIH) - Referencia a Ragnhild Therese Nordvik. http://www.saih.no/ Bistand/Nicaragua/index.html

19. Iglesia Morava - Referencia a Lorraine Parsons. http://www.moravian.org.uk/pages/moravian frame $1 . h t m l$ ?centre $=$ archive.html

20. Iglesia Morava - Referencia a Provincia del Norte de América (Belén) y de la provincia de East West. Indies. http://www.moravianchurcharchives.org/

21. Instituto de Jamaica para el fomento de la literatura, la ciencia ay el arte, en http://www.instituteofjamaica. org.jm/

22. Instituto Tecnológico de Massachusetts - Referencia a Ken Hale (qpd). Departamento de Lingüística y Filosofia. http://web.mit.edu/linguistics/events/ tributes/hale/index.html

23. Johns Hopkins University Press - Referencia a Proyecto MUSE. http://muse.jhu.edu/

24. Karl Offen //http://members.cox.net/bobbieo/ko/ tour.html

25. Latin American Studies Association (LASA). http:// lasa.international.pitt.edu/

26. Museo Británico, En: http://www.britishmuseum.org/

27. Oberlin College, Ohio - Referencia Baron Pineda. http://www.oberlin.edu/lared/faculty.htm

28. Revista ANIDE (Asociación Nicaragüense de Escritoras) http://www.escritorasnicaragua.org

29. Stanford University Press - Referencia a Stanford University Press. http://www.sup.org/

30. Texas Tech University - Referencia a Phillip Dennis.

31. The National Archives in Washington, DC, en http:// www.archives.gov/dc-metro/washington/

32. The National Archives, UK, en http://www. nationalarchives.gov.uk/records/

33. Turkulka - Refrencia a Maricela Kauffman, Diccionario de la lengua Rama. http://www. turkulka.net/
34. Universidad de Southampton - Referencia a Jane Freeland del Departamento de Lingüística. http://www.soas.ac.uk/linguistics/events/ deptseminars/28oct2008-a-role-for-sociolinguisticsin-language-documentation-the-case-of-northernsumu-in-nicarag.html

35. Universidad de Austin - Referencia a Edmund Gordon. Departamento de Estudios sobre África y la Diáspora Africana. http://www.utexas.edu/research/ eureka/departments/view.php?id=113

36. Universidad de Colonia - Referencia a Barbara Potthast. Departamento de Historia de Ibérica y América. http://uk-online.uni-koeln.de/cgi-bin/ show.pl/page?uni $=1 \& \mathrm{i} \mathrm{nr}=13 \& \mathrm{f} \mathrm{nr}=4 \& \mathrm{id}=490$

37. Universidad de Colonia - Referencia a IHILA Instituto de Historia Ibérica y Latinoamericana. http://www.ihila.uni-koeln.de/

38. Universidad de Lyon - Referencia a Colette Grinevald y Bénédicte Pivot, ambas del Laboratorio de Dinámica del Lenguaje. http:// www.ddl.ish-lyon.cnrs.fr/presentation/index. asp? Langue $=$ FR\&Page $=$ Objectifs

39. Universidad de Purdue - Referencia a Elena Benedicto. Colegio de Artes Liberales. http:// www.cla.purdue.edu/english/directory/Faculty/ Benedicto, Elena.html

40. Universidad de Troms $\varnothing$ - Referencia a los programas: (1) PRO 03 / 99 Cultural Revitalisation and Marine resources in the Atlantic Coast of Nicaragua. (2) PRO 59 / 2003 Cultural Revitalization, Environment and Sustainable Productive Systems of Indigenous Peoples in the Caribbean Coast of Nicaragua. URACCAN Nicaragua. (3) NUFUPRO-2007/10088 Competence Building through Quality Education and Research in Central America and the Caribbean. URACCAN Nicaragua. http://www2.uit.no/ikbViewer/page/ansatte/ organisasjon/artikkel?p document id $=120260 \& p$ dimension $\mathrm{id}=88199 \& p$ menu $=65794 \& p$ lang $=2$

41. Universidad de Tulaine - Referencia a Hortensia Calvo. http://library.tulane.edu/about/contact/staff/ HortensiaCalvo; http://web.mit.edu/anthropology/; http://web.mit.edu/linguistics/

42. Universidad de York - Referencia a Centre for Research on Latin America and the Caribbean (CERLAC). http://www.yorku.ca/cerlac/

43. University of Texas Press - Referencia a http://www. utexas.edu/utpress/ 
Los hallazgos en los sitios electrónicos visitados confirman que es necesario crear una estrategia que permita referenciar esos centros o universidades donde existen estudios de interés sobre la Costa Caribe, con el objetivo de poder inventariar los documentos y, además, establecer mecanismos éticos y de reciprocidad de las instituciones y personas que investigan, con el fin que se realicen consultas, procesos de validación y devolución de sus resultados a las comunidades y poblaciones que en un momento anterior fueron la fuente de sus datos.

\section{Transcripción del registro de datos en formato Excel}

La transcripción de los datos a tablas de Excel, la cual contiene 1,760 entradas $(60.94 \%$ de los registros fotográficos), fue sumamente lenta; entre las causas se encuentran (a) duplicidad de registros entre las distintas bibliotecas y colecciones, (b) la escasa cultura de completar el pie de imprenta en los documentos, particularmente en aquellos materiales de firmas editoriales efimeras, así como monografias, manuscritos y publicaciones domésticas (impresiones personales, por ejemplo), y (c) adecuación del trabajo en filas y columnas y aspectos técnicos, con base a sugerencias de UNESCO-Costa Rica.

La ficha catalográfica inicial contenía tres tipos de registros: (a) monografias, (b) publicaciones seriadas, (c) trabajos finales y (d) documentos inéditos. En esta investigación se unificó completamente las tres fichas en una misma base de datos.

La caracterización del material sistematizado se ha organizado de acuerdo a las siguientes categorias: idioma, temas, tesauro UNESCO y pueblos estudiados.

La tabla de Excel consta de 21 columnas que integran los tres formatos sugeridos. Esto, con el fin de unificar la base datos en un solo archivo.

La ficha catalográfica podrá ser transportada a los programas de base datos más modernos y brinda la posibilidad de hacer impresiones hoja por hoja de cada registro.

\section{Tipos de estudios culturales que deben publicarse y/o traducirse en dirección múltiple}

Una revisión exhaustiva, rigurosa y corroborada en la validación conduce hacia el establecimiento de criterios más precisos para la publicación, traducción, adaptación

\section{Gráfico 1: Modelo de ficha catalográfica.}

\begin{tabular}{|c|c|c|}
\hline 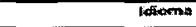 & & \\
\hline \multicolumn{3}{|l|}{ Autor personat! } \\
\hline \multicolumn{3}{|l|}{ Awtor comparativo } \\
\hline \multicolumn{3}{|l|}{ Tituto } \\
\hline \multicolumn{3}{|l|}{ Euffetion } \\
\hline \multicolumn{3}{|l|}{ 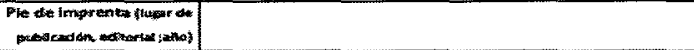 } \\
\hline \multicolumn{3}{|l|}{ Oescriperion fisfes } \\
\hline \multicolumn{3}{|l|}{$s=$} \\
\hline \multicolumn{3}{|l|}{ Votumen } \\
\hline \multicolumn{3}{|l|}{ Nürneror } \\
\hline \multicolumn{3}{|l|}{ Colerectibn } \\
\hline \multicolumn{3}{|l|}{ Notiss } \\
\hline \multicolumn{3}{|l|}{ Descriptores } \\
\hline \multirow{3}{*}{ Miterdis } & Thonfatica general & \\
\hline & 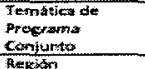 & \\
\hline & 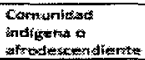 & \\
\hline \multirow{2}{*}{ Oun: manteions } & Fortina & \\
\hline & Persanas & \\
\hline \multicolumn{3}{|l|}{ Setion } \\
\hline Utricantion fistica & & \\
\hline
\end{tabular}

y re-impresión de textos. Incluso surgieron textos no considerados en el informe preliminar que se incluyen en esta selección.

\section{Publicación en español}

1. Gurdián, Galio Claudio. Mito y memoria en la construcción de la fisonomía de la comunidad de Alamikamba. Faculty of the Graduate School of the University of Texas at Austin. 2001.

\section{Traducción}

2. Inglés a Español // Edmund Gordon. Disparate Diasporas: Identity and Politics in an AfricanNicaraguan Community (review). University of Texas Press. 1998.

3. Inglés a Español // William J. Sorsby, The British Superintendency of the Mosquito Shore, 17491787. Tesis doctoral, University of London, 1969.

4. Inglés a Español // Charles R. Hale. Resistance and Contradiction Miskitu Indians and the Nicaraguan State, 1894-1987. Stanford University Press. 1994.

5. Inglés a Español // Inglés a Español // Richard Magnus. 1974 The Prehistory of the Miskito Coast of Nicaragua: A Study in Cultural Relationships. Ph.D. Dissertation in Anthropology. Yale University. 
6. Alemán a Español // Walter Lehmann. ZentralAmerika, Teil I, Die Sprachen Zentral-Amerikas in ihren Beziehungen zueinander sowie zu SudAmerika und Mexiko. Berlin: Dietrich Reimer. 1920.

7. Inglés a Español // Terry Breverton Trefforest The first American Novel. Part I The journal of Penrose, Seaman by William Williams Part II The Autor, the Book and the Letters in the Lilly Library. Printed in Wales by J\&P Davison, Copyright 2007.

\section{Edición nueva y/o ediciones actualizadas}

8. Diccionarios bilingües/trilingües de las cinco lenguas
9. Diccionario de cada lengua: miskito, sumomayangna, rama, garífuna, kriol.

10. Gramática de cada lengua: miskito, sumomayangna, rama, garífuna, kriol.

11. Colección de cuentos tradicionales en cada lengua: miskito, sumo-maynagna, rama, garífuna, kriol.

\section{Obras inéditas.}

12. Curar, editar y publicar la obra poética y literaria de Ronald Brooks cuya salvaguarda es Irene Vidaurre (Bluefields).

13. Gregorio Smutko. Diario inédito. Una fotocopia del manuscrito se encuentra en el Colegio Santa Inés de Waspam. PUBLICAR

\section{CONCLUSIONES}

1. Se encuentran realizadas las fichas catalográficas de cada una de las publicaciones relativas a la cultura de la Costa Caribe de Nicaragua y sus diversos pueblos, revelando los temas prioritarios para el Programa Conjunto.

2. Se encuentra compilado el material consultado en una bibliografia general que indica el tema, el periodo histórico y el grupo cultural sobre el cual versan las investigaciones.

3. Se encuentran identificadas las áreas de investigación que, debido a la escasez de información disponible, requieren de una atención prioritaria por parte del Fondo de Investigaciones para la revitalización cultural.

4. Se ha elaborado la propuesta para traducir e imprimir textos que se encuentran en otras lenguas ajenas a las de uso en la Costa Caribe y que dada su relevancia pueden ser traducidos.

5. Se encuentran identificados los centros de documentación y/o bibliotecas ubicados en el exterior que por sus relaciones históricas son depositarios de estudios culturales sobre la Costa Caribe de Nicaragua e identificadas las vias de comunicación necesarias con dichas instancias para generar colaboraciones futuras.

6. Se ha generado una propuesta pertinente y relevante de publicaciones sobre la cultura de la Costa Caribe de Nicaragua y sus diversos pueblos.

\section{PRIORIDADES}

Los temas prioritarios que surgen en esta investigación se han identificado durante las entrevista.

1. Antropología-Etnología

2. Arqueología

3. Autonomía como proceso

4. Cultura de paz y Conflictos

5. Cultura y cosmovisión

6. Demarcación territorial

7. Demografía

8. Derecho consuetudinario

9. Economía

10. Educación intercultural bilingüe
11. Etnobotánica

12. Etnohistoria

13. Género / feminismo / liderazgo

14. Geográfica política

15. Identidad

16. Lingüística

17. Literatura

18. Medicina Tradicional

19. Mestizaje

20. Migración
21. Pedagogía

22. Política

23. Procesos fundacionales de las comunidades y pueblos

24. Racismo

25. Religión y establecimiento de las iglesias

26. Sociolingüística

27. Temas agrarios

28. Tradición oral

29. Tradición y folklore 


\section{PROPUESTA PARA EL RESGUARDO DEL ACERVO}

Las acciones que se proponen desarrollar para el resguardo del acervo bibliográfico de la Costa Caribe y su difusión son las siguientes:

- Fondo de Investigaciones para la Revitalización Cultural.

- Apoyar la investigación de tipo historiográfico con énfasis en los procesos fundacionales de los pueblos.

- Favorecer la investigación tendiente a recuperar la sabiduría ancestral y la memoria colectiva.

- Profundizar en los estudios lingüísticos con el fin de utilizarlos en la revitalización de las lenguas indígenas $\mathrm{y}$ afrodescendientes.

- Estimular la investigación sobre costumbres, tradiciones, sistema de creencias, organización social, economía, relaciones sociales y de parentesco.

- Animar la investigación en derecho consuetudinario y su aplicación en las comunidades donde está vigente.

- Motivar la realización de inventarios sobre los ecosistemas naturales y su aprovechamiento racional y sostenible en las comunidades.

- Promover la creación artística y literaria como reflejo de la cosmovisión de cada comunidad y pueblo residente en la Costa Caribe de Nicaragua.

- Comisión Rectora / Posibles áreas de intervención para el impulso de nuevas investigaciones culturales, arqueológicas, creativas, así como traducciones pertinentes.

- Organizar un sistema de prioridades para el desarrollo de nuevas investigaciones culturales que atiendan los vacíos y las brechas encontradas en la presente sistematización sobre los estudios culturales.

- Promover la creación de redes de apoyo a la producción de investigaciones académicas sobre temas culturales.

- Desarrollar iniciativas que permitan el acceso libre y directo de la producción escrita, a todas y todos los pobladores de la Costa Caribe de Nicaragua, a través de un sistema de bibliotecas regionales y municipales.

- Continuar con los estudios de tipo arqueológico que permitan tener las evidencias sobre el origen de nuestros pueblos, su cultura, creencias y costumbres.

- Abrir espacios para la socialización de la producción científica, artística y literaria en la Costa Caribe de Nicaragua.

Cabe señalar finalmente que en los aspectos institucionales se contó con el apoyo eficaz del Director del Instituto Nicaragüense de Cultura Arq. Luis Morales Alonso; instancias de UNESCO en Nicaragua y Costa Rica, Rectores y ViceRectores de URACCAN y BICU.

\section{SIGLAS Y ACRÓNIMOS UTILIZADOS}

BICU Bluefields Indian and Caribbean University

CADI Centro de Arqueología, Documentación e Investigación de la UNAN-Managua.

CIDCA Centro para la Investigación y Documentación de la Costa Atlántica

IHNCA-UCA Instituto de Historia de Nicaragua y de Centroamérica - Universidad Centroamericana

INC Instituto Nicaragüense de Cultura

PROIMMSE Programa de Investigaciones Multidisciplinarias sobe Mesoamérica y el Sureste

UNESCO Organización de las Naciones Unidas para la Educación, la Ciencia y la Cultura

URACCAN Universidad de las Regiones Autónomas de la Costa Caribe de Nicaragua 